\title{
Effect of Left Versus Right Radial Artery Approach for Coronary Angiography on Radiation Parameters in Patients with Predictors of Transradial Access Failure
}

\author{
Binita Shah, MD, MS ${ }^{a}$, Joseph Burdowski, MD, Yu Guo, MA ${ }^{b}$, Bryan Velez de Villa, BS ${ }^{a}$, \\ Andrew Huynh, BS ${ }^{a}$, Meena Farid, BS ${ }^{a}$, Mansi Maini ${ }^{a}$, Claudia Serrano-Gomez, MDa, Cezar \\ Staniloae, MDa, Frederick Feit, MDa, Michael J. Attubato, MD ${ }^{\mathrm{a}}$, James Slater, MDa, and John \\ Coppola, MDa \\ aDivision of Cardiology, Department of Medicine, New York University School of Medicine, New \\ York, NY \\ bDivision of Biostatistics, Department of Population Health, New York University School of \\ Medicine, New York, NY
}

\begin{abstract}
Left transradial approach (TRA) for coronary angiography is associated with lower radiation parameters than right TRA in an all-comers population. The aim of this study was to determine the effects of left versus right TRA on radiation parameters in patients with predictors of TRA failure. Patients with predictors of TRA failure ( $\geq 3$ of 4 following criteria: age $\geq 70$ years, female sex, height $\$ 64$ inches, hypertension) referred to TRA operators were randomized to either right $(n=50)$ or left ( $\mathrm{n}=50$ ) TRA, while those referred to transfemoral approach (TFA) operators were enrolled in a prospective registry $(n=50)$. The primary endpoint was the radiation measure of dose area product (DAP). In an intention-to-treat analysis, DAP (34.1 Gy ${ }^{*} \mathrm{~cm}^{2}$ [24.9-45.6] vs $41.9 \mathrm{~Gy}^{*} \mathrm{~cm}^{2}$ [27.3-58.0], $\mathrm{p}=0.08$ ), fluoroscopy time (3.7 $\mathrm{min}$ [2.4-6.3] vs $5.6 \mathrm{~min}$ [3.1-8.7], $\mathrm{p}=0.07)$, and operator radiation exposure (516 uR [275-967] vs. $730 \mathrm{uR}$ [503-1165], p=0.06) were not significantly different between left and right TRA, but total dose (411 mGy [310-592] vs 537 mGy [368-780], $\mathrm{p}=0.03$ ) was significantly lower with left versus right TRA. Radiation parameters were lowest in the TFA cohort (DAP $24.5 \mathrm{~Gy}^{*} \mathrm{~cm}^{2}$ [15.7-33.2], $\mathrm{p}<0.001$; fluoroscopy time $2.3 \mathrm{~min}$ [1.5-3.7], $\mathrm{p}<0.001$; operator radiation exposure $387 \mathrm{uR}$ [264-557]; total dose $345 \mathrm{mGy}$ [250468], $\mathrm{p}=0.001$ ). Results were similar after adjustment for differences in baseline characteristics. In conclusion, median measures of radiation were overall not significantly different between left versus right TRA in this select population of patients with predictors of TRA failure. All measures of radiation were lowest in the TFA group.
\end{abstract}

Corresponding author, Binita Shah, 227 E $30^{\text {th }}$ Street, Office 835, New York, NY 10016, Telephone: 212-263-4235, binita.shah@nyumc.org.

Publisher's Disclaimer: This is a PDF file of an unedited manuscript that has been accepted for publication. As a service to our customers we are providing this early version of the manuscript. The manuscript will undergo copyediting, typesetting, and review of the resulting proof before it is published in its final citable form. Please note that during the production process errors may be discovered which could affect the content, and all legal disclaimers that apply to the journal pertain.

The authors have no conflicts of interest in relation to this manuscript. 


\section{Keywords}

transradial artery approach; coronary angiography; radiation

There is a growing trend to perform invasive coronary angiography and percutaneous coronary interventions via transradial approach (TRA) versus transfemoral approach (TFA) [1]. Although this is partly due to patient preference and associated earlier ambulation times, recent large randomized trials demonstrate decreased rates of bleeding and access-site complications, as well as a reduction in major adverse cardiovascular events in the setting of acute coronary syndrome, with TRA versus TFA when performed by experienced operators [2-5]. Left radial artery (LRA) access results in significantly lower parameters of radiation than right radial artery (RRA) access in an all-comers population, likely due to the associated lesser degree of subclavian artery tortuosity [6]. However, the vast majority of TRA is performed via RRA due to greater ease for the operator. Certain patient characteristics are associated with TRA failure and include greater age, female sex, short stature, and a history of hypertension [6-8]. It is uncertain whether LRA confers a similar advantage over RRA in this high-risk population. The aim of this study is to evaluate the effect of LRA versus RRA on parameters of radiation during invasive coronary angiography in patients with predictors of TRA failure. A secondary aim of this study is to compare radiation parameters associated with TRA versus TFA in this patient population.

\section{Methods}

This study evaluated patients referred for coronary angiography between August 2012 and April 2015 at a single tertiary care center. Patients referred to TRA operators $(n=100)$ were randomized to LRA or RRA, while those referred to TFA operators were consecutively enrolled in a prospective single-arm cohort $(n=50)$. Eligibility criteria included the presence of $\geq 3$ of the following 4 characteristics: age $\geq 70$ years, female sex, $\$ 64$ inches in height, and a history of treated hypertension. Exclusion criteria included 1) prior coronary artery bypass graft surgery, 2) inability to attempt cannulation of the left or right radial artery (e.g. abnormal Allen's test, presence of arterio-venous fistula), 3) need for emergency cardiac catheterization, or 4) participation in another study (Figure 1). Patients provided written informed consent, and the New York University School of Medicine Institutional Review Board approved the study. This investigator-initiated trial is registered at ClinicalTrials.gov (identifier: NCT01707524).

Operators in the current study either use a TRA $(n=5)$ or TFA $(n=3)$ as their primary approach due to experience in that respective approach, and the TRA operators have performed at least 100 procedures via the radial artery. Also in the current study, although TRA operators are facile with both RRA and LRA, standard approach in the cardiac catheterization laboratory is RRA for comfort, with the exception of cases with a left internal mammary artery graft or a known reason for which RRA would be difficult (e.g. pulse not palpable or history of right subclavian stenosis). However, for the purposes of this study, operators were agreeable to use either RRA or LRA. Coronary angiography was performed on an Artis Zee coronary angiography system equipped with software version 
VC14 and a ceiling mounted lead shield (Siemens AG, Germany). Access was obtained using either a 5 or 6 french hydrophilic sheath. Use of catheters, camera angles and collimation were per operator preference. Pulsed fluoroscopy was used at a frame rate of 15 frames per second. Contrast was administered via an automated injector (MEDRAD, MEDRAD Inc., Pittsburgh, Pennsylvania). The use of a RadPad® (Worldwide Innovations $\&$ Technologies Inc., Kansas City, Kansas) protective drape was encouraged when available.

Patient demographics were self-reported, and anthropometric data were measured by trained clinical nurses or study investigators. Pertinent medical history and use of anti-hypertensive agents were obtained from review of the electronic medical system and confirmed by patient interview. Baseline laboratory data was performed in routine clinical laboratories within 30 days of the procedure. Procedural data were collected in real-time.

The primary endpoint was dose area product (DAP) measured in $\mathrm{Gy}^{*} \mathrm{~cm}^{2}$. Secondary endpoints included total radiation dose measured in $\mathrm{mGy}$, fluoroscopy time measured in minutes, and operator radiation exposure measured in $\mu \mathrm{R}$ by a dosimeter placed in the left upper pocket of the lead apron worn by the primary operator. All parameters of radiation were recorded immediately after diagnostic coronary angiography was completed.

Sample size was calculated based on observational data of mean DAP $67.79 \mathrm{~Gy}^{*} \mathrm{~cm}^{2}$ during coronary angiography performed via RRA in our cardiac catheterization laboratory. We expected a $20 \%$ decrease with LRA in this study's population. However, DAP is not normally distributed and, therefore, log-transformed DAP values were used for sample size calculation (mean $3.71 \pm 0.34$; estimated $5 \%$ decrease of log-transformed mean). Based on the above assumptions, and a two-sided two sample t-test, the total sample size required to achieve $80 \%$ power at the 0.05 significance level was estimated to be 50 in each group.

Categorical variables are presented as proportions and compared between LRA and RRA groups using Fisher's exact or chi square test, while continuous variables are presented as median [interquartile range] and compared between LRA and RRA groups using Mann Whitney test. Comparisons across the LRA, RRA, and TFA groups were made using chi square test for proportions and Kruskal-Wallis test for continuous variables. Linear regression analysis was used to determine the effect of LRA versus RRA on radiation parameters after adjustment for baseline variables significantly different between LRA and RRA groups. Significance level was set at 0.05 , and statistical analyses were performed on an intention-to-treat basis using Statistical Package for the Social Sciences 21.0 (IBM Corporation, Armonk, NY) and SAS 9.3.

\section{Results}

Baseline demographic and clinical characteristics of the LRA, RRA, and TFA groups are shown in Table 1 . The proportion of patients with age $\geq 70$ years was significantly lower, while the proportion of patients with height $\$ 44$ inches was significantly higher, in the LRA versus RRA groups. There was no significant difference in proportion of female sex or history of hypertension, and the proportion of patients that met all 4 inclusion criteria did not significantly differ between LRA versus RRA groups ( $34 \%$ vs $48 \%, \mathrm{p}=0.22$ ). Procedural 
characteristics of the LRA, RRA, and TFA groups are shown in Table 2. In the LRA group, 2 subjects crossed over to RRA due to lack of arterial canalization and 1 subject crossed over to TFA due to severe spasm of the radial artery. In the RRA group, 3 subjects crossed over to left TRA and 2 subjects crossed over to TFA due to lack of arterial canalization, while 1 subject crossed over to TFA due to a right subclavian occlusion diagnosed after arterial canalization.

DAP, total radiation dose, fluoroscopy time, and operator radiation exposure in the LRA and RRA groups are shown in Figure 2. DAP, total radiation dose, fluoroscopy time, and operator radiation exposure was 19\%, 23\%, 34\%, and 29\% lower, respectively, in the LRA versus RRA group. The association between LRA/RRA and radiation measures were further assessed using multivariable linear regression analysis with adjustment for proportion of patients with age $\geq 70$ years or height $\$ 64$ inches. DAP and fluoroscopy time remained not significantly different between the LRA and RRA groups. After the adjustments, the estimated mean DAP for LRA was $10.1 \mathrm{~Gy}^{*} \mathrm{~cm}^{2}$ [95\% confidence interval (CI) $-23.9 ;+3.8$ ] lower than RRA ( $\mathrm{p}=0.15$ ) and the estimated mean fluoroscopy time for LRA was $1.8 \mathrm{~min}$ [95\% CI $-4.0 ;+0.5]$ lower than RRA ( $\mathrm{p}=0.13$ ). Total radiation dose remained significantly different with estimated mean total dose $156 \mathrm{mGy}[95 \%$ CI -303; -9] lower in the LRA versus RRA group $(\mathrm{p}=0.04)$.

Median DAP, total radiation dose, fluoroscopy time, and operator radiation exposure was $24.5 \mathrm{~Gy}^{*} \mathrm{~cm}^{2}$ [15.7-33.2], $345 \mathrm{mGy}$ [250-468], $2.3 \mathrm{~min}$ [1.5-3.7], and $387 \mathrm{uR}$ [264-557] in TFA group, all of which were significantly lower than the LRA and RRA groups $(\mathrm{p}<0.001)$.

\section{Discussion}

This is the first prospective randomized study to evaluate radiation parameters by the site of arterial access in patients with predictors of TRA failure. Measures of radiation were overall not significantly different between LRA and RRA in this select patient population made up of elderly, short, hypertensive, female patients.

Several studies have compared LRA with RRA in an all-comer population. One single center prospective observational study of 1032 patients demonstrated no significant difference in the rate of major adverse cardiac and cerebral events, rate of procedural success, and contrast volume in LRA versus RRA groups [9]. However, the number of catheters used and fluoroscopy time were significantly lower in the LRA group. Another single center study randomized 1000 patients to either LRA or RRA and demonstrated no difference in the rate of complications, rate of procedural success, DAP, total procedural time, and number or catheters used but significantly lower fluoroscopy time with LRA [10]. This was thought to be due to a significantly lower rate of operator-reported subclavian tortuosity in the LRA versus RRA group. The TALENT study randomized 1540 patients at two centers to either LRA or RRA [6]. In the 1467 patients undergoing diagnostic coronary angiography, LRA resulted in lower DAP and fluoroscopy time than RRA. The Randomized Evaluation of Vascular Entry Site and Radiation Exposure (REVERE) trial, on the other hand, randomized 1493 patients undergoing coronary angiography at a tertiary care center in India 1:1:1 to 
LRA, RRA, or TFA and demonstrated no significant differences in radiation exposure between the three groups in this "all-comers" population [11].

The majority of operators, though, continue to choose RRA likely because of the similar procedural success rates and greater comfort level associated with operating while standing on the right side of the patient. Thus, studies have investigated potential factors that may influence the degree of difficulty in performing a coronary angiogram via LRA versus RRA. A pre-specified subgroup analysis of the TALENT study demonstrated that the significant differences in radiation parameters between LRA and RRA were notable in patients $\geq 70$ years of age, which, in turn, was an independent predictor of right subclavian artery tortuosity [6]. On the other hand, there was only a trend towards lower radiation exposure with LRA versus RRA in patients $<70$ years of age. A retrospective analysis of 2341 patients who underwent RRA identified older age, female sex, shorter stature, history of systemic hypertension, nonsmoker status, and a higher body mass index as independent predictors of severe right subclavian artery tortuosity [7]. Another retrospective single-center study of 2100 patients who underwent percutaneous coronary intervention via TRA by low-tointermediate volume TRA operators determined the primary predictors of failure as age $\geq 75$ years, female sex, short stature, and history of coronary artery bypass graft surgery [8].

The benefits and rate of procedural success with TRA increase with operator experience [3, 12]. In the current study, subjects with predictors of TRA failure were selected for evaluation, and only those referred to primary TRA operators were randomized to LRA versus RRA, while those referred to primary TFA operators were enrolled in a prospective single-arm cohort. However, there remain limitations to the current study. First, due to the selective nature of the study population, the study is relatively small with only 150 subjects. Second, though patients referred for TRA were randomized, there were a significantly greater number of subjects with age $\geq 70$ years in the RRA group and a significantly greater number of subjects with height $\$ 64$ inches in the LRA group. It is not certain whether or not these two predictors of TRA failure are equally weighted. Adjustment for these variables, though, resulted in an overall similar conclusion. Third, approach to coronary angiography was per operator discretion. Although use of collimation and use of radiation protection drape were not different between LRA and RRA groups, the use of a universal diagnostic catheter and number of cineangiography pictures were significantly lower in the LRA group, while the total number of catheters used to cannulate the coronary arteries were significantly greater in the LRA group. These variables were not included in the linear regression model due to the uncertainty of whether or not these differences were associated with operator preference or the effect of LRA versus RRA. Nonetheless, this is the only prospective randomized trial of LRA versus RRA in patients with predictors associated with TRA failure and one of the few randomized cardiovascular clinical trials to have a significant number of elderly and female patients.

\section{Acknowledgments}

We acknowledge the contributions of Vivek Kumar, MD and Manjiri Tule, MD of NYU School of Medicine to the data collection. Binita Shah was partially funded by a NYU CTSA grant UL1TR000038 from the National Center for Advancing Translational Sciences (NCATS), NIH. Part of the data analysis and statistical support was provided by New York University School of Medicine Cardiovascular Outcomes Group. 


\section{Disclosures}

Dr. Shah receives research funding from Siemens Medical Solutions, and Dr. Coppola is a consultant for Terumo and speaker for Medtronic.

\section{References}

1. Baklanov DV, Kaltenbach LA, Marso SP, Subherwal SS, Feldman DN, Garratt KN, Curtis JP, Messenger JC, Rao SV. The prevalence and outcomes of transradial percutaneous coronary intervention for ST-segment elevation myocardial infarction: analysis from the National Cardiovascular Data Registry (2007 to 2011). J Am Coll Cardiol. 2013; 61:420-426. [PubMed: 23265340]

2. Brueck M, Bandorski D, Kramer W, Wieczorek M, Höltgen R, Tillmanns H. A randomized comparison of transradial versus transfemoral approach for coronary angiography and angioplasty. JACC Cardiovasc Interv. 2009; 2:1047-1054. [PubMed: 19926042]

3. Jolly SS, Yusuf S, Cairns J, Niemelä K, Xavier D, Widimsky P, Budaj A, Niemelä M, Valentin V, Lewis BS, Avezum A, Steg PG, Rao SV, Gao P, Afzal R, Joyner CD, Chrolavicius S, Mehta SR. RIVAL trial group. Radial versus femoral access for coronary angiography and intervention in patients with acute coronary syndromes (RIVAL): A Randomized, Parallel group, Multicenter Trial. Lancet. 2011; 377:1409-1420. [PubMed: 21470671]

4. Romagnoli E, Biondi-Zoccai G, Sciahbasi A, Politi L, Rigattieri S, Pendenza G, Summaria F, Patrizi R, Borghi A, Di Russo C, Moretti C, Agostoni P, Loschiavo P, Lioy E, Sheiban I, Sangiorgi G. Radial versus femoral randomized investigation in ST elevation acute coronary syndromes: The RIFLE STEACS study. J Am Coll Cardiol. 2012; 60:2481-2489. [PubMed: 22858390]

5. Valgimigli M, Gagnor A, Calabro P, Frigoli E, Leonardi S, Zaro T, Rubartelli P, Briguori C, Andò G, Repetto A, Limbruno U, Cortese B, Sganzerla P, Lupi A, Galli M, Colangelo S, Ierna S, Ausiello A, Presbitero P, Sardella G, Varbella F, Esposito G, Santarelli A, Tresoldi S, Nazzaro M, Zingarelli A, de Cesare N, Rigattieri S, Tosi P, Palmieri C, Brugaletta S, Rao SV, Heg D, Rothenbühler M, Vranckx P, Jüni P. MATRIX Investigators. Radial versus femoral access in patients with acute coronary syndromes undergoing invasive management: a randomized multicentre trial. Lancet. 2015; 385:2465-2476. [PubMed: 25791214]

6. Sciahbasi A, Romagnoli E, Burzotta F, Trani C, Sarandrea A, Summaria F, Pendenza G, Tommasino A, Patrizi R, Mazzari M, Mongiardo R, Lioy E. Transradial approach (left vs right) and procedural times during percutaneous coronary procedures: TALENT study. Am Heart J. 2011; 161:172-179. [PubMed: 21167351]

7. Cha KS, Kim MH, Kim HJ. Prevalence and clinical predictors of severe tortuosity of right subclavian artery in patients undergoing transradial coronary angiography. Am J Cardiol. 2003; 92:1220-1222. [PubMed: 14609604]

8. Dehghani P, Mohammad A, Bajaj R, Hong T, Suen CM, Sharieff W, Chisholm RJ, Kutryk MJ, Fam NP, Cheema AN. Mechanism and predictors of failed transradial approach for percutaneous coronary interventions. JACC Cardiovasc Interv. 2009; 2:1057-1064. [PubMed: 19926044]

9. Dominici M, Diletti R, Milici C, Bock C, Garg S, De Paolis M, Ambrosio G, Boschetti E. Left radial versus right radial approach for coronary artery catheterization: a prospective comparison. $\mathrm{J}$ Interv Cardiol. 2012; 25:203-209. [PubMed: 22272568]

10. Norgaz T, Gorgulu S, Dagdelen S. A randomized study comparing the effectiveness of right and left radial approach for coronary angiography. Catheter Cardiovasc Interv. 2012; 80:260-264. [PubMed: 22334420]

11. Pancholy SB, Joshi P, Shah S, Rao SV, Bertrand OF, Patel TM. Effect of vascular access site choice on radiation exposure during coronary angiography: The REVERE Trial (Randomized Evaluation of Vascular Entry Site and Radiation Exposure). JACC Cardiovasc Interv. 2015; 8:1189-1196. [PubMed: 26210808]

12. Le J, Bangalore S, Guo Y, Iqbal SN, Xu J, Miller LH, Coppola J, Shah B. Predictors of access site crossover in patients who underwent transradial coronary angiography. Am J Cardiol. 2015; 116:379-383. [PubMed: 26026865] 


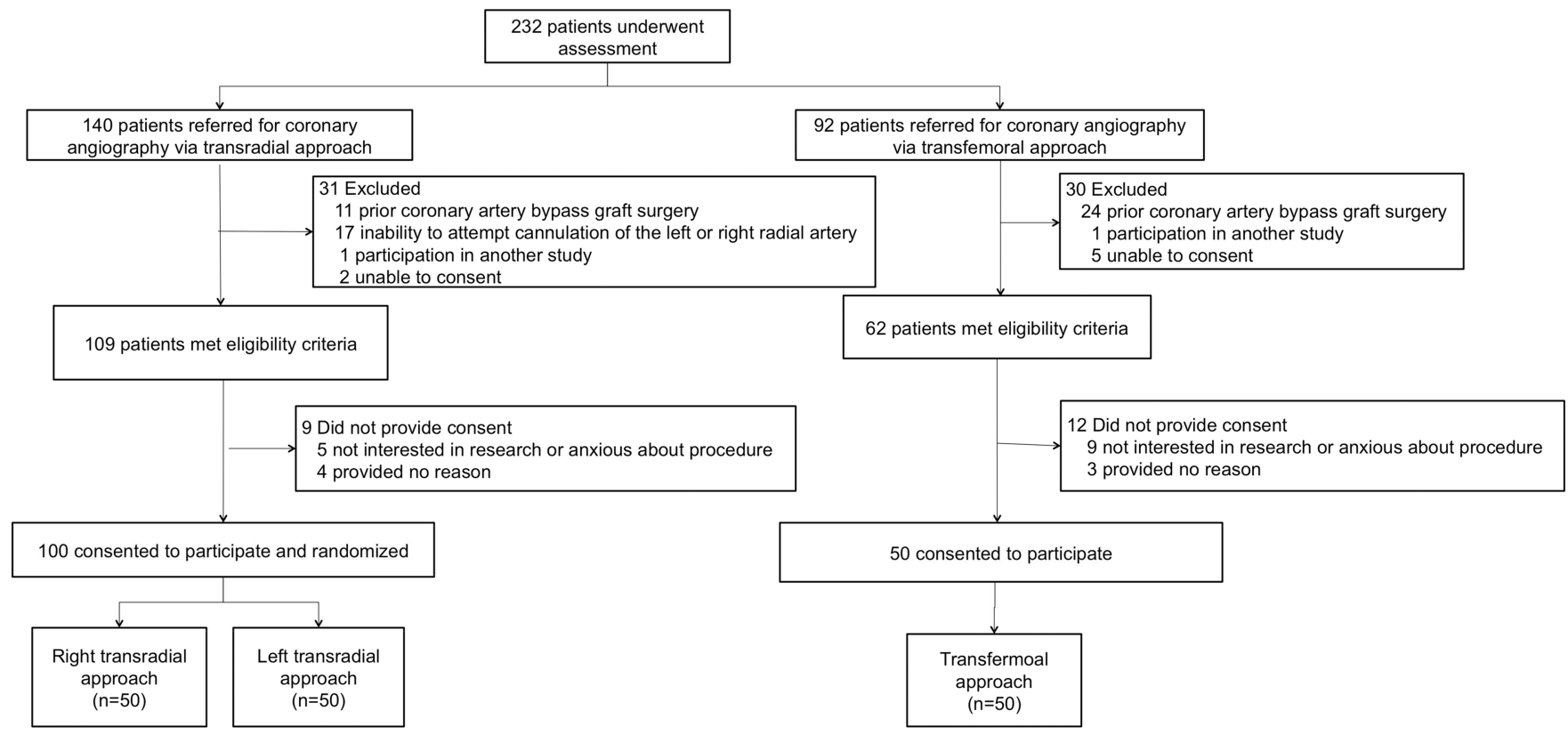

Figure 1.

Screening, enrollment, and randomization of study population 
A)

C)

Figure 2. right or left TRA

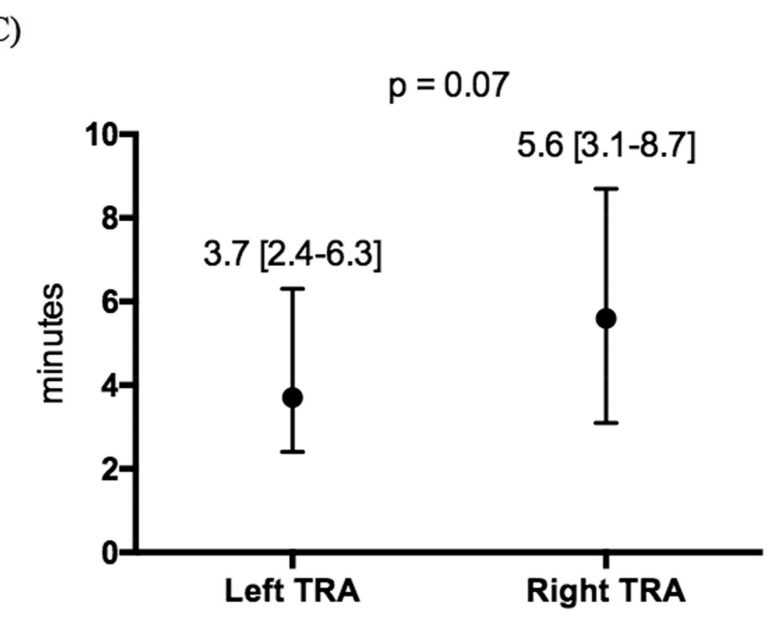

B)

$$
p=0.08
$$

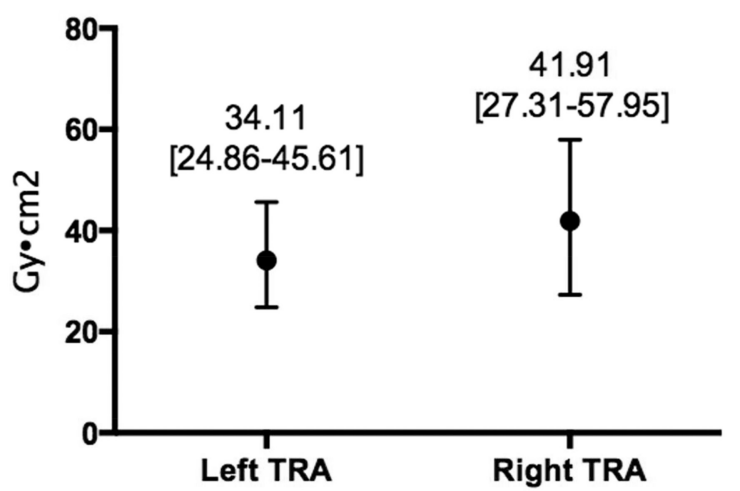

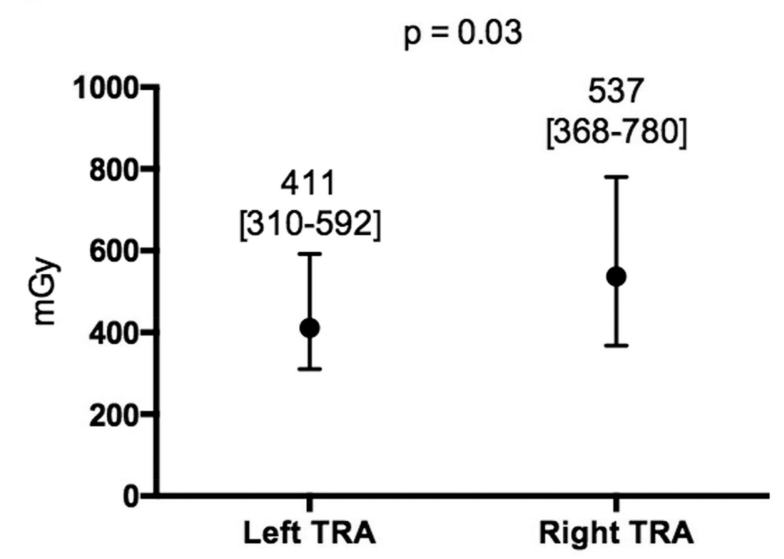

D)

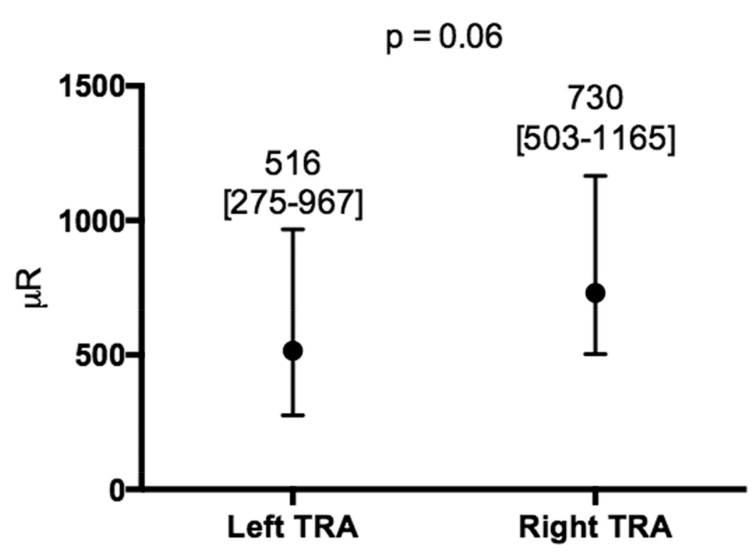

Dose area product (A), total radiation dose (B), fluoroscopy time (C), and operator radiation exposure (D) of patients with predictors of transradial approach (TRA) failure randomized to 


\section{Table 1}

Baseline demographic and clinical characteristics of patients with predictors of transradial approach (TRA) failure randomized to right or left TRA or enrolled in the transfemoral approach (TFA) registry

\begin{tabular}{lcccc}
\hline Variable & $\begin{array}{c}\text { Left TRA } \\
(\mathbf{n}=\mathbf{5 0})\end{array}$ & $\begin{array}{c}\text { Right TRA } \\
(\mathbf{n = 5 0})\end{array}$ & $\begin{array}{c}\text { p- } \\
\text { value }^{*}\end{array}$ & $\begin{array}{c}\text { TFA } \\
(\mathbf{n}=50)\end{array}$ \\
\hline Age (years) & $69[62-75]$ & $75[70-79]$ & 0.006 & $72[65-78]$ \\
Age $\geq 70$ years & $24(48 \%)$ & $38(76 \%)$ & 0.007 & $29(58 \%)$ \\
Women & $47(94 \%)$ & $44(88 \%)$ & 0.49 & $44(88 \%)$ \\
White non-hispanic & $8(16 \%)$ & $6(12 \%)$ & 0.83 & $22(44 \%)$ \\
Black non-hispanic & $12(24 \%)$ & $10(20 \%)$ & & $13(26 \%)$ \\
Hispanic & $20(40 \%)$ & $21(42 \%)$ & & $8(16 \%)$ \\
Asian & $10(20 \%)$ & $13(26 \%)$ & & $6(12 \%)$ \\
Height (cm) & $157[152-160]$ & $157[152-163]$ & 0.45 & $158[155-163]$ \\
Height 64 inches & $50(100 \%)$ & $44(88 \%)$ & 0.03 & $43(86 \%)$ \\
Weight (kg) & $72[63-81]$ & $71[63-79]$ & 0.96 & $73[62-81]$ \\
Body mass index (kg/m $\left.{ }^{2}\right)$ & $29.5[26.3-33.2]$ & $28.6[26.7-32.2]$ & 0.86 & $29.8[26.0-32.0]$ \\
Abdominal circumference (cm) & $107[97-118]$ & $107[99-115]$ & 0.87 & $104[97-113]$ \\
Prior myocardial infarction & $5(10 \%)$ & $6(12 \%)$ & 1.0 & $3(6 \%)$ \\
Prior percutaneous coronary intervention & $9(18 \%)$ & $9(18 \%)$ & 1.0 & $10(20 \%)$ \\
Hypertension ${ }^{\dagger}$ & $45(90 \%)$ & $47(94 \%)$ & 0.72 & $48(96 \%)$ \\
Hypercholesterolemia ${ }^{\#}$ & $26(52 \%)$ & $27(54 \%)$ & 1.0 & $34(68 \%)$ \\
Diabetes mellitus & $20(40 \%)$ & $27(54 \%)$ & 0.23 & $15(30 \%)$ \\
Peripheral artery disease & $3(6 \%)$ & $6(12 \%)$ & 0.49 & $1(2 \%)$ \\
Creatinine (mg/dL) & $0.8[0.7-1.0]$ & $0.8[0.7-1.0]$ & 0.75 & $1.0[0.8-1.1]$ \\
Normal left ventricular ejection fraction & $46(94 \%)$ & $45(90 \%)$ & 0.43 & $42(84 \%)$ \\
\hline
\end{tabular}

Continuous variables are shown as median interquartile range

Categorical variables are presented as $\mathrm{n}(\%)$

*

comparison of right versus left TRA

${ }^{\dagger}$ Hypertension was defined as a clinical diagnosis of hypertension and on antihypertensive medications

${ }^{\#}$ Hyperlipidemia was defined as a clinical diagnosis of hyperlipidemia and on lipid-lowering agents 


\section{Table 2}

Baseline procedural characteristics of patients with predictors of transradial approach (TRA) failure randomized to right or left TRA or enrolled in the transfemoral approach (TFA) registry

\begin{tabular}{lcccc}
\hline Variable & $\begin{array}{c}\text { Left TRA } \\
(\mathbf{n}=50)\end{array}$ & $\begin{array}{c}\text { Right TRA } \\
(\mathbf{n = 5 0})\end{array}$ & $\begin{array}{c}\text { p- } \\
\text { value }\end{array}$ & $\begin{array}{c}\text { TFA } \\
(\mathbf{n}=50)\end{array}$ \\
\hline Access site failure & $3(6 \%)$ & $5(10 \%)$ & 0.72 & 0 \\
Difficulty navigating access artery & $8(16 \%)$ & $12(24 \%)$ & 0.45 & $2(4 \%)$ \\
Use of universal catheter & $10(20 \%)$ & $24(48 \%)$ & 0.006 & 0 \\
Use of collimation & $11(22 \%)$ & $18(26 \%)$ & 0.82 & $9(18 \%)$ \\
Use of radiation protection drape & $45(90 \%)$ & $47(94 \%)$ & 0.72 & $46(92 \%)$ \\
Number of cineangiography pictures & $5.6 \pm 1.6$ & $6.6 \pm 1.7$ & 0.001 & $5.8 \pm 1.5$ \\
$\quad$ Number of flat cines & $3.1 \pm 1.4$ & $3.5 \pm 1.8$ & 0.39 & $3.5 \pm 1.5$ \\
$\quad$ Number of angulated cines & $2.5 \pm 1.5$ & $3.1 \pm 1.5$ & 0.05 & $2.3 \pm 1.2$ \\
Total number of catheters used to cannulate the coronary arteries & $2.3 \pm 0.9$ & $2.0 \pm 1.0$ & 0.03 & $2.2 \pm 1.0$ \\
Number of catheters to cannulate the right coronary artery & $1.2 \pm 0.5$ & $1.3 \pm 0.8$ & 0.75 & $1.0 \pm 0.2$ \\
Number of catheters to cannulate the left coronary artery & $1.2 \pm 0.6$ & $1.1 \pm 0.4$ & 0.35 & $1.2 \pm 1.0$ \\
Contrast used (cc) & $60 \pm 22$ & $68 \pm 31$ & 0.09 & $58 \pm 17$ \\
\hline
\end{tabular}

Continuous variables are shown as mean \pm standard deviation

Categorical variables are presented as \% (n) comparison of right versus left TRA 